\title{
Symbols, SI Units and Physical Quantities within the Scope of Sap Flow Studies
}

\section{Raoul Lemeur ${ }^{(1)}$, Enrique Fernández ${ }^{(2)}$ and Kathy Steppe ${ }^{(1)}$}

(1) Laboratory of Plant Ecology, Department of Applied Ecology and Environmental Biology, Ghent University, Coupure links 653, 9000 Ghent, Belgium

(2) Instituto de Recursos Naturales y Agrobiología, Avenida Reina Mercedes 10, 41012 Sevilla, Spain

Keywords: SI units, plant-water nomenclature, sap flow nomenclature

\begin{abstract}
Some confusion was observed during the $7^{\text {th }}$ International Workshop on Sap Flow (Seville, Spain, 21-24 October 2008) with respect to the use of symbols, units and physical quantities in presentations and during discussions. It was therefore decided at the end of the workshop that a technical note would be very useful with the aim to summarize the basics of the "Système International des Unités (SI)" and to focus on particular aspects that are relevant for sap flow studies. Starting from a number of standard papers that have been published in the past, an extra effort was made to put sap flow nomenclature against the physical background of plant-water relationships, of water flow in the soil-plant-atmosphere continuum and of transport equations for mass, heat and hydraulic flow. Information is given on the application of SI units and the main SI conventions. Tables are included for practical use of basic and derived SI units and for common abbreviations encountered in sap flow studies. An overview of a coherent nomenclature for sap flow studies, together with definitions of sap flow quantities, symbols and units is given as well.
\end{abstract}

\section{INTRODUCTION}

During the $7^{\text {th }}$ International Workshop on Sap Flow (Seville, Spain, 21-24 October 2008) it became clear that participants frequently did not exactly speak the same language or used the same nomenclature when they were discussing their studies on sap flow phenomena and related topics. Some confusion could be observed when symbols, units and even physical concepts were used during their presentations. Scientific communication was sometimes difficult, especially during discussions held after a presentation. At the end of the Seville meeting it was therefore concluded that a technical note would be useful with the aim to summarize the basics of the "Système International des Unités" (official English translation: "International System of Units”, or referred to as the standard system of SI units), and to focus on some particular aspects that are relevant for sap flow studies.

A decimal system of weights and measures was already proposed as early as 1670 by Gabriel Mouton, a French mathematician and vicar of the St Paul's church at Lyon (France). The metric system was finalized during the French revolution (from 1789 till 1799). At that time this system stirred considerable controversy as it illustrated the 
"power of reason and rationality" and, as such, was defying the "power of God". The SI system is now supervised by the "Comité International des Poids et Mesures" (CIPM) which comes under the authority of the "Conférence Générale des Poids et Mesures" (CGPM) in which delegates represent the countries that signed the SI convention (52 member states and 26 associated members). In principle CIPM meets every year at Sèvres (near Paris) and the conference convenes every four to six years to discuss specific topics of the SI system (the $23^{\text {rd }}$ conference was held in 2007).

Many papers on the use and rules of the SI system have already been published in the past. For more details one could refer to a standard work such as published by Taylor (1995) and Salisbury (1996) amongst others. Other publications define the SI rules adopted by a scientific journal or society (e.g. Agricultural and Forest Meteorology, -see Reifsneider et al., 1991- ; American Society of Agronomy, Crop Science Society and Soil Science Society, -see Anonymous, 1998-; ...). Very relevant information on unified nomenclature for sap flow measurements has also been published by Edwards et al. (1996) and several interesting overviews can be found on the internet (e.g. //physics.nist.gov/cuu: "SI Unit Rules and Style Conventions"). The particular preferences and principles of nomenclature developed in this paper agree to some extent with the recommendations made by Edwards et al. (1996). An extra effort has been made here to put sap flow nomenclature against the physical background of plant-water relationships and the fundamental theory of transport equations. Concepts of water flow in the soil-plant-atmosphere continuum, as reviewed by Fernández and Clothier (2002), have been incorporated as well.

\section{BASIC AND DERIVED SI UNITS}

\section{Physical quantities, numerical values and symbols for units}

Research communicates usually by mathematic expressions which might have the following form:

$$
m=1.25 \mathrm{~kg}
$$

where $m$ indicates the physical quantity "mass", 1.25 is a numerical value and "kg" is the symbol for the corresponding SI unit. According to SI rules the symbols for quantities should be a single letter written in italics (i.e. " $m$ ") and the quantity is equal to a numerical value (i.e. 1.25) multiplied by the unit (i.e. kg). As such, the unit can be subjected to algebraic manipulations as shown in the equation below:

$$
m / \mathrm{kg}=1.25
$$

Remark that the symbol for the SI unit, as well as the numerical value, are written in upright roman characters; and that symbols of SI units are never pluralized. A space is always maintained between the numerical value and the symbol of the unit. The symbol is never followed by a period, except at the end of a sentence.

Care should also be taken to specify a correct number of significant digits for the numerical value. The significant digits are determined by the relative accuracy of the instrument that is used for quantifying the physical quantity. The relative accuracy in plant science studies is usually limited to $1 / 1000$ leading to four significant digits for numerical values, as most instrumentation does not provide a better relative accuracy. 
Data expressed by numbers containing more significant digits are therefore misleading and give a false impression of accuracy.

The symbols for physical quantities may contain subscripts or superscripts but, contrary to the italics for the quantity, the subscript or superscript must be written with an upright roman character (example: vapour pressure of water in air is “ $e_{\mathrm{a}}$ ”).

\section{SI base units and use of prefixes}

Table 1 shows the seven base units of the SI system for length (m), mass (kg), time (s), electric current (A), thermodynamic temperature (K), luminous intensity (cd) and amount of substance (mol); together with the two supplementary units for plane angle (rad) and solid angle (sr).

The system of base units contains some difficulties as "mass" expressed in $\mathrm{kg}$ cannot be measured directly and is therefore often replaced by "weight". What is actually measured is the force exerted by the mass due to the acceleration of the earth's gravitational field. Both terms can be exchanged, but in scientific texts preference should be given to "mass". Another problem with "kg" is its name. The name contains the prefix "kilo", which indicates that the unit equals 1000 grams and implies that "g" is the basic SI unit instead of "kg".

Easy communication for and understanding of the physical quantities involved in the same phenomena or processes also asks for application of a "scale rule" whereby the numerical values have more or less the same magnitude. This can be obtained by up- or down-scaling the SI units through use of prefixes that point respectively to multiples or submultiples of the unit. It means that, by proper choice of multiples or submultiples, the numbers should be contained within a scale of 0.1 to 100 .

Table 2 gives an overview of the SI prefixes, together with their symbol and multiplication factor. Originally, multiples were supposed to have Greek names and capital letter symbols. The latter convention is only true for multiples higher than "kilo". The submultiple nomenclature should refer to Latin names and lower case letters. The result is even more ragged as historical attitudes and entrenched customs played again a role.

\section{Derived SI units}

In addition to the SI base units, several derived units of common usage are allowed in the SI system. They have special names which sometimes refer to the scientists who introduced the corresponding physical quantity in their research. Units derived from such a proper name are always capitalized, while the full name of the unit is not (e.g. a force of 1 newton is written as $1 \mathrm{~N}$ ). Table 3 lists a number of physical quantities for which derived units are used and that are expressed by combinations of base units. The base units in such combinations are separated by a space, although it is common in the US to replace the space by a multiplication product dot. Derived units that contain a quotient can express this with a slash (i.e. the solidus symbol "/”), but preference is given to the use of negative exponents.

\section{Units that are not officially part of the SI system}

It is recognized by the CGPM that, due to tradition, several units are frequently used without being part of the basic or derived units. Physical quantities for which this is the case are: 
1. Time. Although second is the SI unit, multiples can be used that have proper names such as minute (symbol "min”), hour (symbol "h”), day (symbol “day”), week (symbol "wk") and year (symbol "yr"). This can be done for descriptive purposes, but when time is used in equations it should be expressed in seconds. A point on the time scale of the year is specified by the day of year (symbol "DOY"). Sometimes "Julian Day" is wrongly used instead of DOY. Remark that Julian Day has a unique astronomical significance as it points to a day on the Julian calendar. This calendar differs from the current one (i.e. the Gregorian calendar) in terms of the number of leap days.

2. Area. Use of hectare or are is very common and is also entrenched in agriculture and forestry, especially in the context of fertilizer applications. Again, this is common sense for more practical oriented publications. If possible, multiples of $\mathrm{m}^{2}$ should be used in more fundamental studies using the equivalences of 1 are $=10^{2} \mathrm{~m}^{2}$ and $1 \mathrm{ha}=10^{4} \mathrm{~m}^{2}$.

3. Volume. Volume is, by preference, expressed in cubic meter $\left(\mathrm{m}^{3}\right)$. This unit is rather large so that the submultiple cubic decimeter $\left(\mathrm{dm}^{3}\right)$ is used in many circumstances. CGPM accepts its equivalent the liter (English : litre) as a special name for the cubic decimeter, but it suggests the symbol "L" instead of the letter "l" (which may be confused with the number " 1 ").

4. Concentration. Some units of concentration for solids in liquids widely used in the past are discontinued within the scope of the SI system. It concerns the units for molar (symbol "M") and molal concentration (symbol “m”), respectively given by :

$$
1 \mathrm{M}=1 \mathrm{~mol} \mathrm{~L}^{-1} \text { for molarity and } 1 \mathrm{~m}=1 \mathrm{~mol} \mathrm{~kg}^{-1} \text { for molality }
$$

The units "M" and "m" of expression (3) should be replaced by the units at the right side of the equation sign.

The symbol for concentration of a substance "i" is written as " $C_{\mathrm{i}}$ ". Acceptable

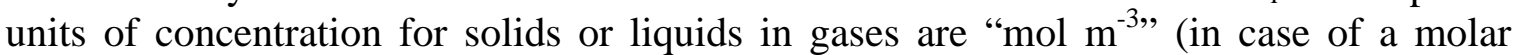

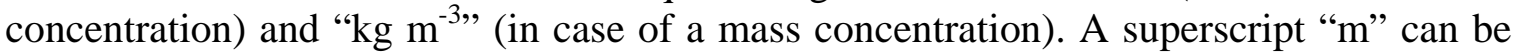
used to specify molar concentration (“ $C_{\mathrm{i}}^{\mathrm{m}}$ ”).

The composition of mixtures can also be defined by the "mole fraction" i.e. the ratio of the number of moles for substance ' $i$ " to the total number of moles present in the mixture. In that case the unit "mol mol" ${ }^{-1 \text { " }}$ should be used. This undimensioned fraction is sometimes written as "\%". The percent symbol is acceptable in the SI system. A space is then left between the numerical value and the \% symbol.

\section{NOMENCLATURE FOR PLANT-WATER RELATIONS}

\section{Plant water status}

The water status of plants can be specified by their water content and water potential. Water content is a quantitative measure expressing the mass of water present in a particular plant component (e.g. per unit of leaf mass, leaf area, stem mass, ...). Water content was widely used in the past, but it has gradually been abandoned in plant science as the water content is not very sensitive to effects of drought and drought stress (small changes between the status of full turgidity and permanent wilting). Nevertheless, the concept of relative water content (symbol " $W_{\mathrm{r}}$ ") is still used and is subject to renewed interest (see below). The relative water content is equal to the actual water content divided by the water content at full turgidity: 


$$
W_{\mathrm{r}}=(\mathrm{f}-\mathrm{d}) /(\mathrm{s}-\mathrm{d})
$$

where $\mathrm{f}, \mathrm{d}$ and $\mathrm{s}$ are respectively the fresh weight, the dry and the saturated weight; and $W_{\mathrm{r}}$ is expressed as an undimensioned fraction or \%. In some studies a different symbol for relative water content is used, i.e. " $\theta$ ".

The water potential is a qualitative measure expressing the availability of water at a particular level in the soil-plant-atmosphere continuum (SPAC). The adjective "potential" refers to the fact that water potential is equivalent with potential energy. As such, it expresses the work that is necessary to move water molecules in a reversible way from a reference level (pure and free water at standard level and pressure) to the SPAC position under consideration. This work deals with several types of forces that are involved during that movement. Therefore, a water potential value (symbol " $\Psi$ ") contains several components, each one linked with a particular force: physical pressure exerted on water (negative or positive component " $\Psi_{\mathrm{p}}$ “), electrostatic attraction of water molecules by solutes (negative component " $\Psi_{\mathrm{s}}$ "), attraction of water molecules by capillary forces (negative component " $\Psi_{\mathrm{m}}{ }^{\prime}$ ) and work against the gravitational field (positive component " $\left.\Psi_{\mathrm{g}}{ }^{\prime}\right)$. The total waterpotential $\Psi$ is then given by :

$$
\Psi=\Psi_{\mathrm{p}}+\Psi_{\mathrm{s}}+\Psi_{\mathrm{m}}+\Psi_{\mathrm{g}}
$$

where $\Psi_{\mathrm{p}}, \Psi_{\mathrm{s}}, \Psi_{\mathrm{m}}$ and $\Psi_{\mathrm{g}}$ are the pressure, solute, matric and gravitational potential respectively. Remark that the symbol for the total water potential has no subscript and that, sometimes, osmotic potential (symbol “ $\Psi_{\pi}$ ”) is used instead of solute potential.

As work equals a force times a displacement, the unit for water potential should, according to Table 3, be " $\mathrm{N}$ m" or joule (" $\mathrm{J}$ ”). To normalize the potential energy for a unit

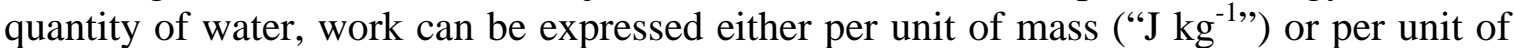

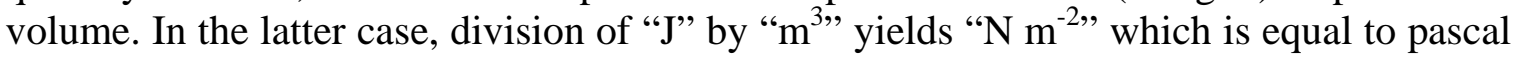
("Pa"). The pressure unit pascal is a logical choice in plant-water relations as it permits the quantification of water flow in plants driven by a pressure gradient (see below: hydraulic flow). Numerical water potential values expressed in Pa give large numbers and use of the multiple mega is suggested (e.g. a soil water potential of $-1.5 \mathrm{MPa}$ is a typical permanent wilting point for crops).

Water content and water potential are interrelated through the concept of capacitance which expresses the ratio of the change in tissue water content to the change in water potential :

$$
C=\mathrm{d} W / \mathrm{d} \Psi
$$

where $C$ is the tissue capacitance, $\mathrm{d} W$ is the change in water content and $\mathrm{d} \Psi$ is the change in water potential. The units of the capacitance are influenced by the definition of water

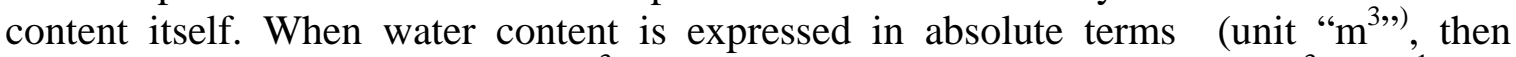
capacitance has the dimension of $\mathrm{m}^{3}$ of water per MPa yielding the unit of " $\mathrm{m}^{3} \mathrm{MPa}^{-1}$ ".

The relationship between water potential or water potential components (ordinate) and water or relative water content (abscissa) can be represented by a curve in the so called "Höffler-Thoday diagrams", in which the capacitance " $C$ " is then equal to the inverse value of the slope of the curve. 


\section{Transport}

The general form of a transport equation is :

Flux $=($ constant $) \times($ driving force $)$

In principle, a flux expresses the amount of a substance passing through a given surface per unit of time. However, some confusion exists in plant science whether "flux" is the same as "flux density" or not? One could refer back to physics where flux and flux density are well known concepts in electromagnetic field theory. In case of a magnetic field, the total magnetic flux (“ $\Phi$ ”) is given by :

$$
\Phi=\iint_{\mathrm{S}} E \cdot \mathrm{d} a
$$

where $E$ is the magnetic field vector expressing the magnetic flux per unit of perpendicular surface and per unit of time and da is an elementary surface. Hence, equation (8) calculates by integration the total flux passing through a given surface $S$ per unit of time; and it clearly illustrates the relationship between a flux and a flux density. Therefore, confusion can be avoided in plant science by accepting the same principle: i.e. flux is the amount through a given surface per unit of time and flux density is the flux per unit of surface. As such, "flux" has a precise mathematical significance and should not be confounded with "flow" which, in a more general way, points to matter, heat or momentum that is in motion (cfr. the science of fluid dynamics).

Sometimes, a specific syntax is used for indicating flux densities by using an upright bold capital (e.g. "C" is commonly used for the flux density of heat by convection -see Monteith and Unsworth, 1990-). However, preference could be given to the overall use of italic characters in mathematical expressions, except for numerical values (see above) and for operators (e.g. derivative) and functions.

\section{Mass flow by diffusion}

Equation (7) is valid for diffusion processes whereby mass flow occurs from a position of high to a position of low concentration. This yields for a one-dimensional diffusion process:

$$
J_{\mathrm{i}}=-D_{\mathrm{i}} \partial C_{\mathrm{i}} / \partial x
$$

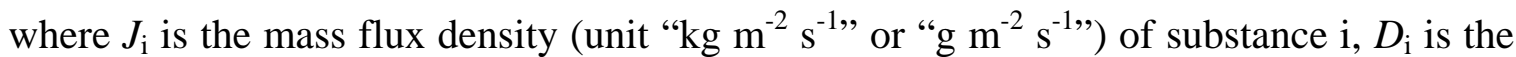

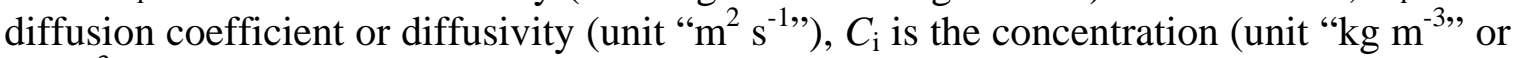

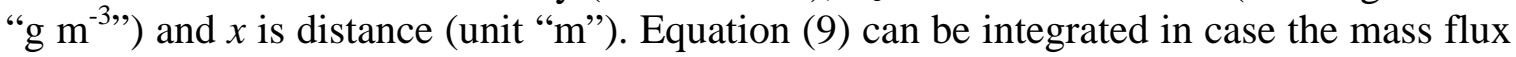
density does not change with distance (and no other driving processes such as temperature or pressure intervene):

$$
J_{\mathrm{i}}=D_{\mathrm{i}}\left(C_{\mathrm{i}, 1}-C_{\mathrm{i}, 2}\right) / \ell \text { or } J_{\mathrm{i}}=\Delta C_{\mathrm{i}} / r_{\mathrm{i}}
$$

where $\Delta C_{\mathrm{i}}$ is the concentration difference over the distance $\ell$ and $r_{\mathrm{i}}$ is the diffusion

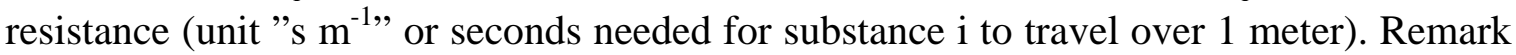
the SI convention whereby the double subscripts used in $C_{\mathrm{i}, 1}$ and $C_{\mathrm{i}, 2}$ are separated by a comma.

The reciprocal of a resistance is called a conductance so that: 


$$
1 / r_{\mathrm{i}}=D_{\mathrm{i}} / \ell=g_{\mathrm{i}}
$$

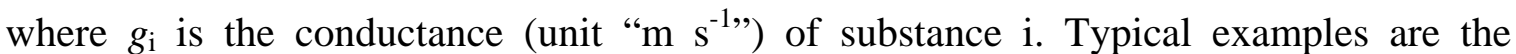
resistance or conductance for water vapour diffusion through the laminar boundary layer prevailing at the upper and lower leaf surfaces. In that case the diffusion coefficient for water vapour in air $\left(D_{\mathrm{v}}=0.242 \cdot 10^{-4} \mathrm{~m}^{2} \mathrm{~s}^{-1}\right.$ at $\left.20^{\circ} \mathrm{C}\right)$ and the thickness of the boundary layer (symbol " $\delta$ ") should be used. It is appropriate to add the adjective "diffusive" (i.e. diffusive resistance or diffusive conductance) to discriminate from the same concepts that are used for the case of hydraulic flow (see below).

\section{Heat flow}

Methodology of sap flow measurements is based on a combination of heat flow and hydraulic flow phenomena. Heat flow by conduction is driven by a temperature gradient and it is described by an equivalent form of equation (9), called Fourier's Law:

$$
J_{\mathrm{h}}=-k \partial \mathrm{T} / \partial x
$$

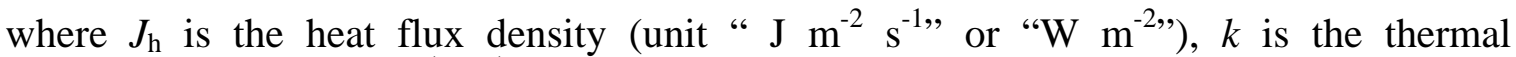

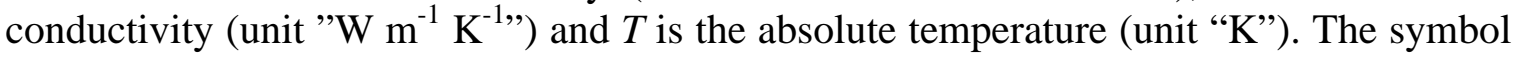
" $J_{\mathrm{h}}$ " for heat flux density is frequently replaced by the symbol " $C$ " or " $H$ " to clearly differentiate from the unit joule (symbol "J").

The concentration of the substance used in equation (9) can now be replaced by a "heat concentration" in this substance, being equal to the product of density of the substance times its heat capacity times its temperature:

$$
J_{\mathrm{h}}=-D_{\mathrm{h}} \cdot \partial\left(\rho c_{p} T\right) / \partial x
$$

or in integrated form:

$$
J_{\mathrm{h}}=D_{\mathrm{h}} \rho c_{p} \Delta T / \ell
$$

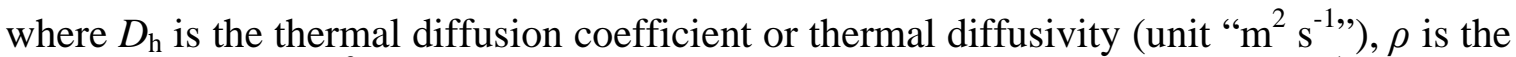

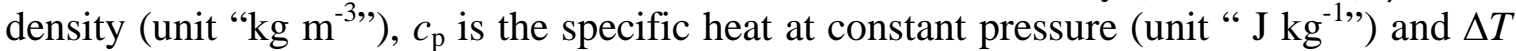
is the temperature difference over distance $\ell$ (unit “m”). Remark that in the SI system the adjective "specific" always points to a quantity per unit of mass (i.e. per kg).

\section{Hydraulic flow}

When concentration is replaced by a hydrostatic pressure, then the transport equations become:

$$
J_{\mathrm{v}}=-L \partial P / \partial x
$$

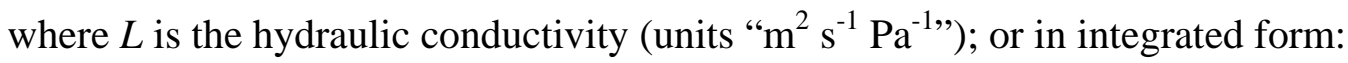

$$
J_{\mathrm{v}}=L \cdot \Delta P / \ell=L_{\mathrm{p}} \cdot \Delta P
$$




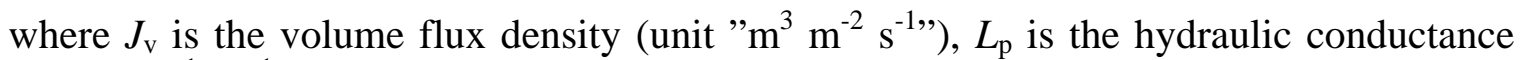

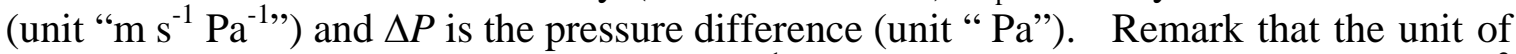

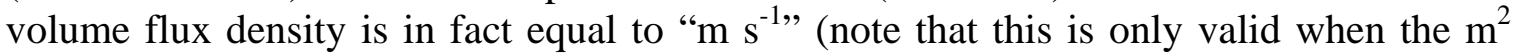
cross-section represents a water surface). In that case volume flux density is a displacement per second or a "flow velocity". As such, volume flux density is frequently substituted by flow velocity. The latter term should, however, be discontinued (see below "Nomenclature for sap flow"). Furthermore, the term "velocity" is in fact a vector quantity for which both the rate of change of the position of water molecules and their direction of movement should be specified. In sap flow studies, one is more concerned with the scalar quantity (only rate of change), which should then be called "speed".

Equation (15) applied to cylindrical (xylem) tubes yields the well-known Poiseuille equation:

$$
J_{\mathrm{v}}=\left(\pi r^{4}\right) /(8 \eta \ell) \cdot \Delta P
$$

where $r$ is the radius of the cylindrical tubes (unit " $m$ ”) and $\eta$ is the dynamic viscosity of the fluid (unit "Pa s"). Identification of equation (16) with equation (17) yields an expression for the hydraulic resistance $(R)$ and hydraulic conductance $(L \mathrm{p})$ :

$$
1 / R=L_{\mathrm{p}}=\left(\pi r^{4}\right) /(8 \eta \ell)
$$

Remark the use of the capital " $R$ ” for hydraulic resistance to discriminate from the diffusive resistance (symbol “ $r$ ”).

When the flow of water in plants is in a steady state regime, then the volume flux density can also be expressed in terms of water potential. For flow in xylem vessels, where osmotic forces can usually be neglected, the flow is driven by the pressure component of the water potential. Hence:

$$
J_{\mathrm{v}}=L_{\mathrm{p}} \cdot \Delta \Psi_{\mathrm{p}}
$$

Equation (19) can be adapted for the case of a dynamic regime for water flow in plants. It requires, in addition to $J_{\mathrm{v}}$, an extra flow of water from storage compartments in the plant. This can be taken into account by inclusion of the change of water content with time. A detailed analysis of dynamic sap flow phenomena is given by Steppe et al. (2006).

\section{NOMENCLATURE FOR SAP FLOW}

\section{Principles}

Appropriate units should comply with the principles and syntax of the SI system explained above. Furthermore, it is indicated that the hydraulic approach is used instead of a mass flow concept since sap flow studies are mainly dealing with transport of water and much less with movement of solutes. It is also important that use of units is independent of the methodology used for sap flow measurements (e.g. heat pulse methods versus methods using continuous heating).

Table 4 gives a synoptic overview of quantities, symbols and units that are relevant within the context of sap flow studies. The link with more fundamental aspects of transport equations is given above. 


\section{Sap flux density}

In principle, sap flow should be expressed as a volume flux density with units of

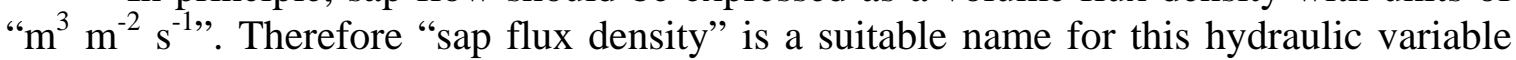
and the symbol could be " $J_{\mathrm{v}}$." An alternative is to use " $J_{\mathrm{p}}$ " to clearly indicate the fact that the hydraulic flow takes place inside a plant.

It has already been mentioned that the unit for volume flux density is in fact equal to " $\mathrm{m} \mathrm{s}^{-1}$ " indicating a displacement per unit of time (note again that this is only valid when the $\mathrm{m}^{2}$ cross-section represents a water surface). For this reason sap flux density has been replaced in many publications by "sap flow velocity" (symbol " $v_{\mathrm{p}}$ ") which, indeed, refers to the speed of the sap flow. As already explained above, the use of "velocity" should be avoided as, in physics, velocity is a vector quantity that implies specification of both a numerical value and a direction.

\section{Sap flux}

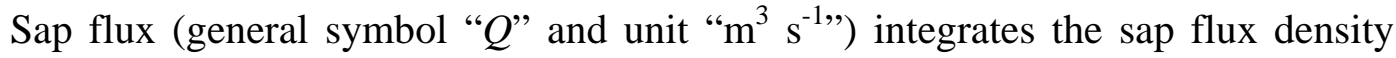
over a given surface $S$, see equation (8):

$$
Q=\iint_{\mathrm{S}} J_{\mathrm{v}} \cdot \mathrm{d} a
$$

The symbol " $Q_{\mathrm{p}}$ " could, eventually, be reserved for the total sap flux of a plant or tree ( $\mathrm{S}$ is then the total sapwood area). The units " $\mathrm{m}^{3} \mathrm{~s}^{-1 \text { " }}$ refer to the rate of change of a volume of water with time. As such, sap flux also corresponds with the notion of a flow rate. Sap flow rate has been used in many publications, although the link between sap flow velocity and sap flow rate is less clear than between sap flux density and sap flux.

Sap flux points to the total amount of water flowing through a given area per unit of time. This means that the area must be specified. In many cases, the area will be equated with the cross-section of the stem, whilst in others it will be the sapwood area. Area integration of sap flux density might be difficult since the cross-section of a stem is composed of conducting and non-conducting parts. The fact that a radial profile of sap flux density exists at the level of the cross-section induces an extra complication encountered with sap flux calculations (Steppe et al., 2009 (this issue)).

One expects that sap fluxes are always directed from soil to atmosphere, but water flow in plants can also be directed towards the soil when soil water potential is very negative, as well as from roots in wetter soil to roots located in drier soil. Different types of reverse flow have been, in fact, described: hydraulic lift, downward siphoning and lateral flow (Fernández and Clothier, 2002; Nadezhdina et al., 2009). Downward and upward sap flux can be indicated respectively by $Q_{\mathrm{p}, \mathrm{u}}$ and $Q_{\mathrm{p}, \mathrm{d}}$. Remark the SI guidelines that double subscripts are separated by a comma.

\section{Cumulative sap flux} over time:

Cumulative sap flux (symbol " $Q$ '”) can be obtained by integrating the sap flux $Q$

$$
Q^{\mathrm{c}}=\int Q \cdot \mathrm{d} t
$$

Studies on irrigation management based on sap flow measurements frequently require data on daily water consumption. Integration of sap flux over time yields a 
volume of water with unit " $\mathrm{m}^{3 \text { ". }}$. For practical applications the irrigation dose is frequently

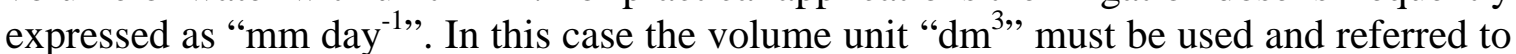
a normalized sap flux per unit of land area $\left(\mathrm{dm}^{3} \mathrm{~m}^{-2}=\mathrm{mm}\right)$.

\section{Unit area}

As sap flux density is expressed per unit area, it is necessary to clearly specify which type of surface area is taken into account. Distinction should be made when a unit of sapwood area is used (symbol " $J_{\mathrm{p}}{ }_{\mathrm{p}}^{\mathrm{s} \text { ”). }}$.

Also, sap flux could be normalized per unit of leaf area above the point of sap flow measurement (symbol " $J_{\mathrm{p}}^{1 \text { ") }}$ ) or per unit of basal area at the measurement point

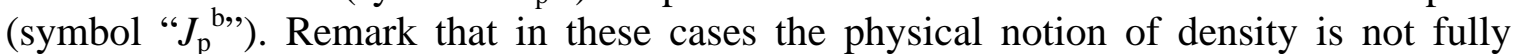
respected as division of the sap flux by the supporting leaf area or by the basal area is a mere normalization of sap flux values.

\section{Sap flow and heat flow}

Some methods for sap flow measurements rely on a combination of heat flow and hydraulic flow in the xylem tissue. These processes are complex since heat flow in the xylem path is not only due to heat conduction but convective transport is very important as well. Heat also interacts with the xylem so that its vertical movement is slowed down in comparison with the vertical mass flow of water. Therefore, when sap flow measurements are carried out sap flux density $J_{\mathrm{p}}$ should be discriminated from heat flux density $J_{\mathrm{h}}$, the latter being always smaller.

\section{Abbreviations for sap flow methodologies}

Abbreviations are commonly used in publications when referring to the methods and instrumentation used to estimate sap flow. A brief overview is given in Table 5 and more extended descriptions can be found on the website listed.

\section{Literature cited}

Anonymous, 1998. Publications Handbook Style Manual. American Society of Agronomy, Crop Science Society of America, Soil Science Society of America. Library of Congress Registration No. 98-074771, p. 73-87.

Edwards, W.R.N., Becker, P. and Čermák, J. 1996. A unified nomenclature for sap flow measurements. Tree Physiology 17: 65-67.

Fernández, J.E. and Clothier, B.E. 2002. Water uptake by plants. The Encyclopaedia of Life Support Systems (EOLSS), Developed under the Auspices of the UNESCO. EOLSS Publishers, Oxford ,UK., www.eolss.net.

Monteith, J.L. and Unsworth, M.H., 1990. Principles of Environmental Physics. Edward Arnold, ISBN 0-7131-2931-X, 291 pp.

Nadezhdina, N., Steppe, K., De Pauw, D.J.W., Bequet, R., Čermák, J. and Ceulemans, R., 2009. Stem-mediated hydraulic redistribution in large roots on opposing sides of a Douglas-fir tree following localized irrigation. New Phytol. (doi: 10.1111/j.14698137.2009.03024.x).

Reifsneider, W.E., McNaughton, K.G. and Milford, J.R. 1991. Symbols, units, notation. A statement of journal policy. Agric. and For. Meteorol. 54:389-397.

Salisbury, F.B. 1996. Units, Symbols and Terminology for Plant Physiology. Oxford University Press, ISBN 0-19-509445-X, 234 pp. 
Steppe, K., De Pauw, D.J.W., Lemeur, R. and Van Rollegem, P.A. 2006. A mathematical model linking tree sap flow dynamics to daily stem diameter fluctuations and radial stem growth. Tree Physiology 26:257-273.

Steppe, K., De Pauw, D.J.W., Saveyn, A., Tahon, P., Nadezhdina, N., Čermák, J. and Lemeur, R. 2009. Radial sap flux profiles and beyond: an easy software analysis tool. Acta Hort. (this issue, accepted).

Taylor, B.N.1995. Guide for the use of the International System of Units (SI). NIST Spec. Pub. 811. Physics Lab., National Institute of Standards and Technology, Gaithersburg (MD), USA. 


\section{Tables}

Table 1. Base and supplementary $\left(^{*}\right)$ units of the "Système International des Unités” (SI units).

\begin{tabular}{lclc}
\hline Physical quantity & Symbol for quantity & SI base unit & Symbol for SI unit \\
\hline & & & \\
Length & $l$ & meter & $\mathrm{m}$ \\
Mass & $m$ & kilogram & $\mathrm{kg}$ \\
Time & $t$ & second & $\mathrm{s}$ \\
Electric current & $I$ & ampere & $\mathrm{A}$ \\
Thermodynamic & $T$ & kelvin & $\mathrm{K}$ \\
temperature & & candela & $\mathrm{cd}$ \\
Luminous intensity & $n$ & mole & $\mathrm{mol}$ \\
Amount of substance & & radian & $\mathrm{rad}$ \\
Plane angle $(*)$ & & steradian & $\mathrm{sr}$ \\
Solid angle $(*)$ & & & $\mathrm{C}$ \\
\hline
\end{tabular}

Table 2. SI prefixes for multiples and submultiples, together with their symbols and multiplication factors.

\begin{tabular}{lcc|lcc}
\hline & Multiples & \multicolumn{3}{c}{ Submultiples } \\
\hline Prefix & Symbol & Factor & Prefix & Symbol & Factor \\
\hline deka & $\mathrm{da}$ & 10 & deci & $\mathrm{d}$ & $10^{-1}$ \\
hecto & $\mathrm{h}$ & $10^{2}$ & centi & $\mathrm{c}$ & $10^{-2}$ \\
kilo & $\mathrm{k}$ & $10^{3}$ & milli & $\mathrm{m}$ & $10^{-3}$ \\
mega & $\mathrm{M}$ & $10^{6}$ & micro & $\mu$ & $10^{-6}$ \\
giga & $\mathrm{G}$ & $10^{9}$ & nano & $\mathrm{n}$ & $10^{-9}$ \\
tera & $\mathrm{T}$ & $10^{12}$ & pico & $\mathrm{p}$ & $10^{-12}$ \\
peta & $\mathrm{P}$ & $10^{15}$ & femto & $\mathrm{f}$ & $10^{-15}$ \\
\hline
\end{tabular}

Table 3. Derived SI units with special names.

\begin{tabular}{llrll}
\hline $\begin{array}{l}\text { Physical } \\
\text { quantity }\end{array}$ & SI name of unit & Symbol & $\begin{array}{l}\text { Definition in } \\
\text { base SI units }\end{array}$ & Equivalent units \\
\hline & & & & \\
Energy & joule & $\mathrm{J}$ & $\mathrm{m} \mathrm{kg} \mathrm{s}^{-2}$ & $\mathrm{~N} \mathrm{~m}$ \\
Force & newton & $\mathrm{N}$ & $\mathrm{m} \mathrm{kg} \mathrm{s}^{-2}$ & $\mathrm{~J} \mathrm{~m}^{-1}$ \\
Power & watt & $\mathrm{W}$ & $\mathrm{m}^{2} \mathrm{~kg} \mathrm{~s}^{-3}$ & $\mathrm{~J} \mathrm{~s}^{-1}$ \\
$\begin{array}{l}\text { Pressure } \\
\text { frequency }\end{array}$ & pascal & $\mathrm{Pa}$ & $\mathrm{m}^{-1} \mathrm{~kg} \mathrm{~s}^{-2}$ & $\mathrm{~N} \mathrm{~m}^{-2}$ or J m \\
\hline
\end{tabular}


Table 4. Proposal of a nomenclature for use in sap flow studies.

\begin{tabular}{|c|c|c|c|}
\hline Quantity & Symbol & Unit & Description / Remark \\
\hline $\begin{array}{l}\text { Mass flux } \\
\text { density }\end{array}$ & $J_{\mathrm{i}}$ & $\mathrm{kg} \mathrm{m}^{-2} \mathrm{~s}^{-1}$ & $\begin{array}{l}\text { Mass flow of substance i along a } \\
\text { concentration gradient }\end{array}$ \\
\hline $\begin{array}{l}\text { Heat flux } \\
\text { density }\end{array}$ & $J_{\mathrm{h}}$ & $\begin{array}{l}\mathrm{J} \mathrm{m}^{-2} \mathrm{~s}^{-1} \\
\text { or } \mathrm{W} \mathrm{m} \mathrm{m}^{-2}\end{array}$ & Heat flow along a temperature gradient \\
\hline $\begin{array}{l}\text { Volume flux } \\
\text { density }\end{array}$ & $J_{\mathrm{v}}$ & $\mathrm{m}^{3} \mathrm{~m}^{-2} \mathrm{~s}^{-1}$ & $\begin{array}{l}\text { Hydraulic flow along a pressure gradient; } \\
\text { symbol } J_{\mathrm{v}} \text { can also be used for sap flux } \\
\text { density }\end{array}$ \\
\hline \multirow[t]{3}{*}{ Sap flux density } & $J_{\mathrm{p}}$ & $\mathrm{m}^{3} \mathrm{~m}^{-2} \mathrm{~s}^{-1}$ & $\begin{array}{l}\text { Volume flux density of sap flow in a } \\
\text { plant/tree }\end{array}$ \\
\hline & $\begin{array}{l}J_{\mathrm{p}}^{\mathrm{s}} \\
J_{\mathrm{p}}{ }^{\mathrm{s}}\end{array}$ & $\begin{array}{l}\mathrm{m}^{3} \mathrm{~m}^{-2} \mathrm{~s}^{-1} \\
\mathrm{~m}^{3} \mathrm{~m}^{-2} \mathrm{~s}^{-1}\end{array}$ & $\begin{array}{l}\text { Sap flux density per unit of sapwood area } \\
\text { Sap flux density per unit of supported leaf }\end{array}$ \\
\hline & $J_{\mathrm{p}}^{\mathrm{b}}$ & $\mathrm{m}^{3} \mathrm{~m}^{-2} \mathrm{~s}^{-1}$ & Sap flux density per unit of basal area \\
\hline \multirow[t]{4}{*}{ Sap flux } & Q & $\mathrm{m}^{3} \mathrm{~s}^{-1}$ & $\begin{array}{l}\text { Integration of sap flux density over a } \\
\text { given surface }\end{array}$ \\
\hline & $Q_{\mathrm{p}}$ & $\mathrm{m}^{3} \mathrm{~s}^{-1}$ & Total sap flux per plant/tree \\
\hline & & & $\begin{array}{l}\text { Superscripts "s", "l” and "b” used as for } \\
\text { sap flux density }\end{array}$ \\
\hline & $Q_{\mathrm{p}, \mathrm{u} ;} Q_{\mathrm{p}, \mathrm{d}}$ & $\mathrm{m}^{3} \mathrm{~s}^{-1}$ & $\begin{array}{l}\text { Total sap flux in respectively upward and } \\
\text { downward direction (double subscript } \\
\text { separated by comma) }\end{array}$ \\
\hline $\begin{array}{l}\text { Cumulative sap } \\
\text { flux }\end{array}$ & $Q^{\mathrm{C}}$ & $\mathrm{m}^{3}$ & $\begin{array}{l}\text { Cumulative sap flux integrated over a } \\
\text { time period }\end{array}$ \\
\hline $\begin{array}{l}\text { Sap flow } \\
\text { velocity }\end{array}$ & $v_{\mathrm{p}}$ & $\mathrm{m} \mathrm{s}^{-1}$ & Suggestion: to be discontinued \\
\hline Sap flow rate & & $\mathrm{m}^{3} \mathrm{~s}^{-1}$ & Suggestion: to be discontinued \\
\hline
\end{tabular}


Table 5. Abbreviations related to the methods to estimate sap flow. Details both on the methods and main references are given in www.wgsapflow.com, section "Methods".

\begin{tabular}{|c|c|c|}
\hline Abbreviation & Meaning & Remarks \\
\hline CAG & calibrated average gradient & $\begin{array}{l}\text { This is a method to calculate low sap } \\
\text { velocities from sap flow records } \\
\text { taken with the CHP method. }\end{array}$ \\
\hline CHP & compensation heat-pulse & $\begin{array}{l}\text { Note that it is "compensation", not } \\
\text { "compensated". }\end{array}$ \\
\hline TD & thermal dissipation & $\begin{array}{l}\text { Commonly referred to as the } \\
\text { Granier's method. }\end{array}$ \\
\hline HFD & heat field deformation & \\
\hline HPV & heat pulse velocity & $\begin{array}{l}\text { Also known as the Green's HPV } \\
\text { system, it can be used either for the } \\
\text { CHP or for the T-max method. }\end{array}$ \\
\hline HRM & heat ratio method & \\
\hline SHB & stem heat balance & \\
\hline THB & trunk sector heat balance & \\
\hline T-max & $\begin{array}{l}\text { T-max ( } \mathrm{T} \text { accounts for } \\
\text { temperature) }\end{array}$ & $\begin{array}{l}\text { Also known as the Cohen's heat- } \\
\text { pulse method }\end{array}$ \\
\hline
\end{tabular}

